\title{
Psicologia nos encontros e interfaces com epistemologias contra-hegemônicas
}

\author{
Catalina Revollo Pardo, (D) I, ${ }^{\star}$ Samira Lima da Costa, (D) I Mancel Martinez Ramos (D) II (Organizadores) \\ ${ }^{I}$ Universidade Federal do Rio de Janeiro, Rio de Janeiro, RJ, Brasil \\ II Universidade de Brasília, Brasília, DF, Brasil
}

Por entender a gravidade do momento histórico que vivemos e o risco de retrocesso epistêmico de recentes avanços, o presente Dossiê responde à necessidade e à urgência da afirmação de existência de conhecimentos que têm sido ao longo de nossa história marginalizados, identificando que tais conhecimentos, atualmente, estão ameaçados de novo silenciamento. É neste sentido que o Programa de Pós-Graduação em Psicossociologia de Comunidades e Ecologia Social da Universidade Federal do Rio de Janeiro, em conjunto com o Programa de Doctorado en Ciencias Sociales e Humanas de la Pontifícia Universidad Javeriana de Bogotá (Colombia), e em parceria com a Fractal: Revista de Psicologia da Universidade Federal Fluminense, apresenta o Dossiê "Psicologia e epistemologias contra-hegemônicas".

A proposta deste Dossiê parte de uma perspectiva inter e transdisciplinar da psicologia, buscando possíveis encontros e interfaces com epistemologias contra-hegemônicas. Esta iniciativa é uma aposta na construção de conhecimento desde uma perspectiva fundamentalmente eclética e interepistêmica. Tal psicologia há muito vem sendo pensada e exercida, no Brasil e na América Latina. Entendemos que, no momento histórico em que este Dossiê é produzido, quando muitos povos, culturas e modos de subjetivação, bem como a própria universidade e suas recentes iniciativas de transformação, estão sendo postos à prova, urge que nos proponhamos a reunião e sistematização de tais conhecimentos, produzidos a partir de experiências e reflexões contra-hegemônicas.

O Dossiê apresenta textos e autores com fortes análises críticas à visão de mundo que vem, ao longo dos séculos, fundando modelos de pensamento e de ação centrados em referenciais limitados, restritos tanto epistemologicamente quanto geográfica e temporalmente. Em contraposição a estes modelos, o Dossiê traz reflexões teórico- metodológicas posicionadas a partir de perspectivas inventivas, polimatizadas e pluriepistêmicas. Os textos apresentam estudos nos quais o campo de pesquisa não se coloca mais como objeto sobre o qual se produz conhecimento; ao contrário, o próprio campo de pesquisa é visto como produtor de conhecimentos, que complementam, transformam e dialogam com o campo epistêmico da academia, produzindo conhecimentos outros.

Objetiva-se, com isso, questionar aquilo que Carvalho (2017) chamou de cânone do saber euro centrado: as rígidas fronteiras disciplinares que excluem ou reduzem os saberes criados e reproduzidos no interior das comunidades, movimentos sociais periféricos e grupos étnicos da América Latina.

No início deste século XXI, D’Ávila Neto (2003) afirmava que as pesquisas em ciências sociais e humanas na América Latina ainda apresentavam certa tendência ao reducionismo, uma vez que tomavam por princípio a lógica de que um único saber se constitui como referencial hegemônico, dando um tratamento genérico e universal aos seres humanos e sociedades, com recortes racistas, classistas e sexistas.

Este posicionamento se traduz em silenciamentos materializados em muitos âmbitos: na organização dos currículos, nos modelos de mercado e racionalidades profissionais, nos modos como se faz pesquisa, na aposta (ou não) naquilo que sabe a comunidade com a qual se trabalha e na formação de novos profissionais e pensadores.

Ainda que a estrutura acadêmica nos desafie continuamente a estabelecer zonas confortáveis de reprodução de conhecimento, desde a segunda metade do século XX muitos pesquisadores e muitas pesquisadoras vêm insistindo na criação de novas formas de ver e produzir conhecimento, garantindo espaço transfronteiriço entre diferentes visões de mundo, investindo na garantia da multiplicidade de cosmovisões e da complexidade de seus entrelaçamentos, subjetividades e polifonias.

Com o intuito de abrir e garantir espaço para as muitas vozes até então silenciadas, este Dossiê traz artigos que pretendem refletir a construção da psicologia e campos afins no encontro com saberes que historicamente têm sido invisibilizados ou manipulados, dando destaque ao lugar de enunciação das múltiplas epistemologias contra-hegemônicas.

O Dossiê está composto por 17 artigos que transitam com um alto teor crítico pelos seguintes temas, que nos apoiam no exercício contínuo de (re)pensar a psicologia: processos urbanos, processos de tradição de povos originários da América Latina e de outras regiões do mundo, gênero, racismo e meio ambiente.

\section{Referências}

CARVALHO, José Jorge de. Uma proposta de estudos culturais na América Latina: inclusão étnica e racial, transdisciplinaridade e encontro de saberes. In: ALMEIDA, Júlia; PATROCÍNIO, Paulo Roberto Tonani do. (Org.). Estudos culturais: legado e apropriações. Campinas, SP: Pontes, 2017. p. 157-190.

D’ÁVILA NETO, Maria Inácia. A porta, a ponte e a rede: reflexões para pensar o conceito de rede e o conceito de comunidade. In: D'AVILA NETO, Maria Inácia; PEDRO, Rosa Maria Leite Ribeiro (Org.). Tecendo o desenvolvimento. Rio de Janeiro: MAUAD, 2003. p. 13-28.

\footnotetext{
*Endereço para correspondência: Universidade Federal do Rio de Janeiro, Departamento de Terapia Ocupacional - CCS. Avenida Ilha do Fundão. Bancários. CEP 21910240 - Rio de Janeiro, RJ - Brasil.E-mail: carevollo@gmail.com, biasam2000@gmail.com, mmancel@yahoo.com.mx
} 